\title{
Hacia la configuración de un sistema de seguridad colectiva ${ }^{1}$
}

https://doi.org/10.21830/9789585318328.01

\author{
Angie Julieth Arenas Piedrahita ${ }^{2}$ \\ Juan Camilo Mejía Prieto ${ }^{3}$ \\ Manuel Rayran Cortés ${ }^{4}$ \\ Escuela Militar de Cadetes "General José María Córdova”
}

\section{Resumen}

El presente capítulo aborda cronológicamente la evolución de la seguridad colectiva, cuyas raíces parten de una concepción imperial que dominó las dinámicas de la guerra en Europa y que, finalmente, desencadenarían la Primera Guerra Mundial. El siglo XX fue marcado por sesgos ideológicos que crearon la bipolaridad propia del periodo y que profundizaron todavía más el realismo político imperante en el sistema internacional. La destrucción dejada por la Segunda Guerra Mundial sería el catalizador que facilitaría la creación de una organización supranacional que finalmente se encargase de garantizar la paz y la seguridad internacionales. Finalmente, la modernidad trae inmensos retos en

1 Este capítulo hace parte de los resultados del proyecto de investigación "Mecanismos del sistema de Naciones Unidas para la resolución de conflictos armados contemporáneos", del Grupo de Investigación en Ciencias Militares de la Escuela Militar de Cadetes "General José María Córdova, registrado con el código COL0082556 de Minciencias. Los puntos de vista y los resultados de este artículo pertenecen al autor y no reflejan necesariamente los de las instituciones participantes.

2 Profesional en Relaciones Internacionales y Estudios Políticos (Universidad Militar Nueva Granada). Magíster en Asuntos Internacionales con énfasis en resolución de conflictos armados (Universidad Externado de Colombia y Escuela de Asuntos Internacionales y Políticas Públicas de Columbia University). Docente universitaria. Sus áreas de investigación son: filosofía política, gobernanza global, teorías de relaciones internacionales, seguridad internacional, conflictos armados contemporáneos, y bioética global. ORCID: https://orcid.org/0000-0002-4054-6417 - Contacto: angie.arenas@esmic.edu.co

3 Profesional en ciencias militares y administrador de empresas. Especialista en conducción y administración de unidades militares. Especialista en administración de recursos militares para la defensa nacional. Magíster en Inteligencia Estratégica (Escuela de Inteligencia y Contrainteligencia). Magíster en Estudios de Defensa (Royal Military College of Canada). ORCID: https://orcid.org/0000-0002-3187-1015 Contacto: juan.mejia@buzonejercito.mil.co

4 Magíster en Ciencias Políticas orientadas a las Relaciones Internacionales con especialidad en Diplomacia y Resolución de Conflictos (Universidad Católica de Lovaina, Bélgica). Docente de la Facultad de Relaciones Internacionales de la Escuela Militar de Cadetes "General José María Córdova". Docente de la Facultad de Finanzas, Gobierno y Relaciones Internacionales (Universidad Externado de Colombia). Sus líneas de investigación son: teoría de las Relaciones internacionales, teoría de los conflictos, seguridad internacional, geopolítica de las potencias y resolución de conflictos. ORCID: https://orcid.org/0000-00033658-2690 - Contacto: manuel.rayran@esmic.edu.co 
materia de seguridad derivados de una nueva forma de conflictividad en la que los actores estatales no se enfrentan entre sí, sino que se enfrentan (o patrocinan) a organizaciones que representan identidades políticas, religiosas, o raciales frente a las cuales la Organización de las Naciones Unidas desafortunadamente no tiene injerencia alguna.

Palabras clave: imperialismo, realpolitik, ONU, política exterior, seguridad colectiva, seguridad internacional.

\section{Introducción}

A lo largo de la historia de la humanidad, y en el marco de las diversas etapas del sistema internacional, las comunidades y los Estados han concentrado todos sus esfuerzos en garantizar la seguridad e integridad de su territorio y su población y, en tiempos más recientes, en garantizar el mantenimiento de la paz y la seguridad internacionales. Esto, debido a la creciente interdependencia ocasionada por la globalización y a las consecuencias devastadoras que dejaron las dos guerras mundiales, evidenciando así la necesidad de crear un sistema de seguridad colectiva, hoy materializado en la Organización de las Naciones Unidas.

Haciendo un breve recorrido por los anales de la historia, en todas las épocas los grupos humanos han buscado eliminar o reducir al máximo las amenazas a su seguridad, concepto que hasta el siglo pasado se entendía desde una noción restringida, que lo circunscribía únicamente a la seguridad nacional, pero que poco a poco ha ido adquiriendo un carácter multidimensional y multidireccional, especialmente luego de la Guerra Fría.

Así las cosas, mientras en el pasado el objeto referente de la seguridad era, por tradición, el Estado-nación, definiendo la seguridad nacional como la capacidad de un país para dar continuidad al normal desarrollo de su vida interna sin interferencias o amenazas de interferencias por parte de potencias extranjeras (Instituto Español de Estudios Estratégicos, 2011), en la actualidad se ha superado esta noción al incluir en la agenda aspectos no militares, proscribiendo así el uso de la violencia como forma de salvaguardar los intereses nacionales, excepto en el caso específico de autodefensa.

En el caso particular de los siglos XX y XXI, estos se han caracterizado por la diversificación y ampliación de las amenazas a la seguridad internacional, 
debido, en gran medida, al rápido avance tecnológico — que, entre otras cosas, ha brindado a las guerras un alto grado de letalidad y una mayor efectividad en términos del daño que ocasionan (especialmente durante el siglo XX)—, así como al crecimiento sin precedentes del comercio y las telecomunicaciones que, a su vez, han permitido interconectar a las más de ocho mil millones de personas que habitan el planeta Tierra.

Teniendo en cuenta lo anterior, y con el fin de comprender la evolución del concepto hasta la configuración de un sistema de seguridad colectiva — establecido mediante la Carta de San Francisco de 1945-, en la primera parte de este capítulo se explicarán los diferentes sistemas de seguridad que han existido en cada época y, acto seguido, se ahondará en el Sistema de Naciones Unidas, como principal objeto de análisis del presente libro.

\section{El imperialismo}

Una de las principales estructuras de seguridad que ha dominado el escenario internacional desde la Edad Antigua es el imperialismo, institución que determinó las dinámicas del sistema de Estados durante la expansión europea, que inició con la Era de los Descubrimientos, a partir del siglo XV, y se prolongó durante toda la Edad Moderna y la Edad Contemporánea hasta los procesos de descolonización, en la segunda mitad del siglo XX.

Si bien es cierto que en la actualidad el concepto de imperio posee una connotación negativa, debido a sus implicaciones históricas y a la consolidación del Derecho Internacional como ente rector de las relaciones internacionales, es importante reconocer el rol de esta institución en la evolución del concepto de seguridad, ya que, debido a la necesidad de expandir sus territorios y, por ende, su poderío en el sistema internacional, las potencias europeas acudieron a políticas imperialistas, que en principio demostraron excelentes resultados.

De allí que el imperialismo sea considerado como la primera estructura de control territorial, caracterizada por dos elementos intrínsecos a su propia naturaleza: organizar y mantener la paz entre las comunidades, tanto al interior como afuera de estas. Lo anterior, teniendo en cuenta que dichas comunidades gozaban del privilegio de autonomía, a cambio de la seguridad que proveía el poder central (Encel, 2011). 
No obstante lo anterior, estas prerrogativas estaban supeditadas a la obediencia y contribución a la seguridad general por parte de las comunidades autónomas, mediante el pago de tributos financieros y el suministro de tropas en tiempos de guerra, así como a su obligación de garantizar la protección exterior del imperio, bloqueando todo intento de invasión de las potencias extranjeras (Hardt \& Negri, 2001).

De acuerdo con la teoría matemática de la historia, de Alexandre Deulofeu (1967), la configuración de los imperios ha tenido siempre un carácter cíclico, en tanto que nacen, crecen y mueren, como los seres vivos. La desintegración de los imperios obedece, entonces, a las luchas y fraccionamientos ocasionados por la conquista del poder, tanto desde adentro como hacia afuera. Así, es posible afirmar que el declive de estos tiene su origen en la hiperextensión estratégica y la consecuente imposibilidad de ejercer control sobre todo el territorio, lo que conlleva endurecer las políticas opresivas y represivas, resquebrajando así la estructura imperial (Kennedy, 2017).

\section{Evolución teórica del imperialismo}

Gran parte de la construcción académica occidental con respecto al imperialismo está erigida desde la perspectiva del Imperio británico. El término "imperialismo" fue originalmente propuesto en la década de 1870 por los opositores del primer ministro británico Benjamin Disraeli (1804-1881). Disraeli no solo sirvió en dos ocasiones como primer ministro, sino que forjó las bases del conservadurismo británico moderno. Sus políticas se consideraron demasiado agresivas y, por tanto, fueron objeto de grandes críticas.

Por otra parte, partidarios del imperialismo como Joseph Chamberlain (1836-1914) rápidamente se apropiaron del término y lo usaron para defender la postura del Reino Unido en el sistema internacional. De tal modo que, mientras que algunos interpretaban al imperialismo desde el idealismo y la filantropía, otros no veían en él más que un evidente interés político y un mecanismo para expandir un agresivo modelo capitalista.

Una de las posturas teóricas más importantes del siglo XX fue propuesta por John A. Hobson (1902), quien consideraba que la libre empresa, piedra angular del capitalismo, tenía un impacto negativo en la mayoría de la pobla- 
ción. De la misma forma, propuso que el financiamiento de imperios en ultramar no solo desperdiciaba recursos que eran necesarios para el desarrollo social, sino que era motivado por los bajos salarios que se pagaban a los trabajadores en el exterior.

Si bien el retorno de la inversión era mejor cuando el capital se enviaba al extranjero, esto desmejoraba las condiciones laborales domésticas; además, aunque los salarios en Gran Bretaña eran más altos que en las colonias, definitivamente no crecían al mismo ritmo. Hobson, eventualmente, concluiría que exportar el capital impone un tope al crecimiento de los salarios y, por tanto, a las condiciones de vida de los trabajadores domésticos. Finalmente, indicaría que solo a través de la intervención tributaria doméstica sería posible ampliar el consumo, crear riqueza, e impulsar un mundo multipolar pacífico y tolerante.

Seis décadas después, el historiador David K. Fieldhouse trató de desvirtuar la crítica hecha por Hobson. La obra de Fieldhouse, Imperialism: An Historiographical Revision (1961), critica el imperialismo previo al siglo XVIII y lo compara con el del siglo XIX, que se desarrolla en una "fase avanzada del capitalismo", con el fin de defenderlo. Para el autor, "el análisis del imperialismo de Hobson es defectuoso: pero el hecho de que fuera así es probablemente el resultado de que él comprendiera [solo] una verdad esencial sobre el movimiento imperial: que este se había vuelto irracional” (p. 209).

Mientras que la crítica de Hobson fue rechazada por amplios sectores de la sociedad británica, fue acogida por notables socialistas y académicos como Lenin (1916), Joseph Schumpeter (1919) y Thorstein Veblen (1903), que representaron al imperialismo como el fin de la libre competencia propuesta por el capitalismo, por tanto, como el cierre del mercado global, en razón a la necesidad de las economías capitalistas de incrementar la inversión, los recursos materiales y la fuerza laboral, de tal forma que se hacen dependientes de la expansión colonial. Durante el resto del siglo XX, hasta la disolución de la Unión Soviética, teóricos marxistas difundieron la idea de que las guerras mundiales habrían sido consecuencia de la lucha entre imperialistas por el control de mercados externos.

En esa línea, el más reciente análisis del imperialismo fue abordado por Walter Rodney (1973) a través del estudio de caso del continente africano. 
Rodney propone que el imperialismo es una fase del capitalismo "en [la] cual, países capitalistas occidentales, los Estados Unidos y Japón establecieron una hegemonía política, económica y militar sobre otras partes del mundo que estando en un 'nivel inferior' no pudieron resistirse a la dominación” (p. 16). Como resultado de lo anterior, el imperialismo "abarcó el mundo entero, una parte siendo los explotados y la otra los explotadores, una parte siendo dominada mientras que la otra se comportaba como señores, una parte haciendo las políticas mientras que la otra era dependiente" (p. 16).

\section{La realpolitik como medio para garantizar la seguridad internacional}

El segundo sistema de seguridad que logró mantener el equilibro del poder en el sistema internacional fue consagrado bajo la práctica de la realpolitik ${ }^{5}$ desde inicios del siglo XIX hasta la Primera Guerra Mundial—, que constituyó una forma de control caracterizada por tener enfrentamientos frecuentemente limitados entre las potencias europeas, originados por las ambiciones de crecimiento de los gobernantes o, en su defecto, por la defensa de los territorios que habían conquistado (Moreau, 2017).

Dicho concepto, introducido por Von Rochau, estaría necesariamente vinculado al contexto de las revoluciones ocurridas en numerosos países europeos en 1848 , en el marco de las cuales se habían insertado con fuerza los movimientos comunistas, socialistas y liberales, pero que también terminaron en fracaso, debido a la represión gubernamental o por errores de sus dirigentes (Medina-Núñez, 2019).

De allí que se tenga la percepción de que este sistema era, en esencia, bastante inestable, puesto que la práctica reina era la creación de alianzas y contraalianzas entre los Estados, de acuerdo con sus propios intereses, los cuales podían variar según las circunstancias. De hecho, en su construcción teórica, Rochau (citado por Medina, 2019) señala cuatro aspectos fundamentales para describir la realpolitik:

5 De acuerdo con la Real Academia de la Lengua Española, la "realpolitik" es entendida como aquella forma de hacer política basada en criterios pragmáticos, al margen de ideologías. 
1) La ley del más fuerte es un factor determinante en la política; 2) la forma más efectiva de un Gobierno es aquella que incorpora a las más poderosas fuerzas sociales dentro del Estado, fortalece sus energías y logra un balance entre ellas; 3) en política, las ideas importan mucho, pero el papel que juegan ha sido malinterpretado porque ideas inmorales o incultas han sido más poderosas que las nobles según la gente se ha aferrado a ellas y las ha conservado con fortaleza; 4) la modernidad ha cambiado la naturaleza del poder del Estado, con la opinión pública actuando de forma más importante que el Zeitgeist (espíritu de la época) para determinar la trayectoria política de una nación. (p. 284)

Ahora bien, aunque este sistema, en efecto, carecía de estabilidad, debido en gran medida al juego de alianzas estratégicas entre los actores protagónicos de las relaciones internacionales, lo que permitía el mantenimiento del equilibrio era justamente la desconfianza mutua que existía entre los Estados, quienes se veían obligados a emprender una carrera armamentista permanentemente, esto, con el fin de estar preparados para una eventual guerra.

Esta forma de interactuar, que John Herz denominó en 1950 como el "dilema de seguridad" desde el realismo político, ayuda a comprender cómo incluso cuando los Estados no pretenden de forma individual hacer la guerra entre sí, el contexto frágil de desconfianza, inseguridad e incertidumbre, sumado al hecho de que no existe una autoridad política central, es suficiente para desatar una guerra; lo que permite entender que la anarquía internacional es una causa indirecta de esta, pues aunque no provoca el inicio específico de ningún conflicto, tampoco erige algún tipo de obstáculo a la ocurrencia de aquel (Terradas, 2009).

Es en este contexto que se hacía necesaria la existencia de una potencia que ejerciera un rol de arbitraje cuando algún país demostrara tener intenciones hegemónicas, papel que desempeñó Gran Bretaña hasta la Segunda Guerra Mundial y que posteriormente fue ejercido por Estados Unidos y la Unión Soviética.

Teniendo en cuenta las características propias de este tipo de sistema de seguridad, el presidente de los Estados Unidos entre 1913 y 1921, Woodrow Wilson, propuso en 1918 los "Catorce Puntos", mediante los cuales buscaba la eliminación de la guerra y el establecimiento de un nuevo orden mundial 
que se caracterizara por la resolución pacífica de los conflictos. Esto, bajo el argumento de que la realpolitik era generadora de conflicto y ocasionaba que los Estados vivieran en un estado permanente de incertidumbre y temor a una posible guerra.

Aunque la propuesta de Wilson tuvo gran acogida y promovió la creación de la Sociedad de Naciones, dicha iniciativa no tuvo éxito debido a dos razones fundamentales: en primer lugar, el Congreso de los Estados Unidos se opuso rotundamente manteniendo una postura aislacionista en su política exterior; $y$, en segundo lugar, las grandes potencias no encontraron los incentivos suficientes para participar en lo que sería esta nueva estructura de seguridad internacional (Mazarr et al., 2018).

Ahora bien, el advenimiento de la Segunda Guerra Mundial, mucho más devastadora que la Gran Guerra, puso de manifiesto la necesidad de crear un organismo de carácter supranacional que garantizara el mantenimiento de la paz y la seguridad internacionales, el cual se vio materializado mediante el tratado internacional conocido como la Carta de San Francisco, de 1945.

\section{La seguridad colectiva}

En el escenario de posguerra de la Segunda Guerra Mundial, caracterizado por el declive de los imperios coloniales europeos y el surgimiento de dos superpotencias en el sistema internacional, surgió un último sistema de seguridad definido como "contrato social” entre los Estados, mediante el cual se fijaron las reglas y mecanismos para la resolución de los posibles conflictos que surgiesen entre ellos.

Esta iniciativa se materializó en la Organización de las Naciones Unidas, la cual, en principio, fue concebida como una organización de carácter supranacional, pero cuya autonomía está supeditada en la actualidad al poder de veto que detentan los cinco miembros permanentes del Consejo de Seguridad (Estados Unidos, China, Rusia, Francia y Reino Unido), es decir, las potencias aliadas que resultaron victoriosas en la Segunda Guerra Mundial. ${ }^{6}$

6 Teniendo en cuenta que la República Popular de China ocupó el lugar de la República de China (Taiwán), en 1971, y Rusia ocupó el lugar de la Unión Soviética, a partir de 1992. 
Pero ¿en qué consistió este proceso de evolución de la seguridad?, y ¿qué se entiende por seguridad colectiva desde un enfoque amplio o multidimensional? De acuerdo con Herrera Lasso y González (1990, como se cita en Tenorio, 2009), el concepto de seguridad desde su concepción tradicional puede ser entendido como

El conjunto de condiciones — políticas, económicas, militares, sociales y culturales - necesarias para garantizar la soberanía, la independencia y la promoción del interés de la nación, fortaleciendo los componentes del proyecto nacional y disminuyendo al mínimo las debilidades que puedan traducirse en ventanas de vulnerabilidad frente al exterior. (p. 173)

Desde este enfoque en particular, la seguridad nacional es entendida como la necesidad de los Estados de mantenerse soberanos frente a los demás a través de la defensa militar, lo que explica por qué después de la Segunda Guerra Mundial se presentó una tendencia a la militarización de la política internacional, que se hacía manifiesta mediante confrontaciones armadas y el intervencionismo de las grandes potencias del sistema internacional en los países de tercer mundo. Aunque cabe aclarar que, en el marco de la Guerra Fría, la seguridad nacional pasó a ser comprendida desde la bipolaridad, donde la amenaza externa común para Occidente era el comunismo.

Como ya se ha mencionado con anterioridad, paralelo a este proceso se dio la configuración de un escenario de seguridad colectiva o "seguridad de todos por todos" (Negretto, 2000, como se cita en Tenorio, 2009), cuyo objeo tivo fundamental era que los Estados renunciaran al uso individual de la fuerza y obtuvieran a cambio la garantía de que las amenazas o el uso de la fuerza de que fueran objeto serían contrarrestadas en su conjunto.

Así las cosas, la creación de la ONU significó que los Estados entregaran la garantía de la seguridad colectiva al Consejo de Seguridad, órgano principal de esta organización, el cual debe determinar la existencia de las amenazas a la paz y la seguridad internacionales, los quebrantamientos a la paz y los actos de agresión, además de estar facultado para tomar determinaciones tales como: tomar medidas provisionales, emitir recomendaciones, acoger medidas pacíficas, bloquear, autorizar el uso de la fuerza armada o adoptar medidas ad hoc (por ejemplo, crear tribunales internacionales para juzgar casos determinados, como en los casos de Ruanda y Yugoslavia). 
Una vez dicho esto, es importante mencionar que el concepto de seguridad colectiva posee un carácter indivisible, en tanto que la inseguridad de cada miembro de la comunidad implica la inseguridad del conjunto societario. En este sentido, cualquier ataque individual debe ser entendido como un ataque a la colectividad, "por cuanto es la sociedad, y no el miembro agredido, quien debe reaccionar ante el agresor" (Tenorio, 2009, p. 176).

$\mathrm{Si}$ bien es cierto que la ONU se creó bajo un enfoque de seguridad tradicional, desde su misma fundación se vislumbraba que esta no podía estar restringida exclusivamente a los aspectos militares, pues había una correlación entre seguridad, desarrollo económico y libertad humana. Es decir que, para garantizar la paz y la seguridad internacionales, la organización debía librar una batalla en dos frentes específicos (Sunga, 2016): la seguridad (freedom from fear), y lo económico y social (freedom from want).

Esto implica, en consecuencia, una visión comprehensiva de la seguridad, en la medida en que se incorporan aspectos económicos, sociales y ambientales a su definición, lo que amplía de forma considerable la concepción tradicional que solamente contempla la integridad física y la soberanía política del Estadonación. Además, el sujeto final de la seguridad ya no es el Estado, sino las personas.

De esta forma, las llamadas nuevas amenazas surgen de la inestabilidad política, la extrema pobreza, de la falta de cohesión social, de la destrucción del medio ambiente, de la biodiversidad y de los recursos naturales; del narcotráfico y las mafias internacionales, del tráfico de armas, de la descomposición del orden público y del terrorismo. Es por ello, que la nueva agenda de la seguridad internacional posee un carácter transnacional y genera una demanda ineludible de mayor cooperación. (Tenorio, 2009, p. 178).

De acuerdo con la visión de seguridad colectiva desde la cual se cimentaron las bases de la Organización de Naciones Unidas, la cooperación internacional es el instrumento que permite: 1) la creación de las condiciones de estabilidad necesarias para las relaciones pacíficas y amistosas entre las naciones, basadas en el respeto al principio de igualdad de derechos y a la libre determinación de los pueblos; 2) el respeto a los derechos humanos y a las libertades fundamentales de las personas, sin ningún tipo de distinción; y 3) el arreglo 
pacífico de controversias e impedir el fortalecimiento de las amenazas contra la paz (Lourdes, 2017).

\section{La Organización de Naciones Unidas}

La intención de regular los conflictos interestatales es tan antigua como el Proyecto de declaración concerniente a las leyes y costumbres de la guerra de 1874 y las Conferencias de la Haya de 1899 y 1907. La necesidad de establecer un cuerpo normativo que limitara las acciones llevadas a cabo durante la guerra era una preocupación en Europa, incluso antes de las devastadores consecuencias de la Primera Guerra Mundial.

En consecuencia, la Conferencia de Paz de París (1919-1920) permitió la creación de la Liga de las Naciones, primera organización intergubernamental concebida bajo la idea de mantener la paz mundial. Aunque esta organización fue exitosa resolviendo algunas disputas territoriales y creando estructuras internacionales enfocadas a la aviación, el correo postal y el control del opio, falló en el cumplimiento de su rol fundamental, ya que carecía de representación por parte de colonias y, por el contrario, gozaba de una inmensa influencia de grandes potencias de la época como Japón, Estados Unidos, la Unión Soviética y Alemania.

Su fracaso como entidad de gobernanza global fue sellado por la imposibilidad de intervenir en la invasión japonesa de Manchuria, en 1931, la segunda guerra ítalo-etíope, de 1935, la segunda guerra sino-japonesa (1937-1945) y la expansión nazi, que finalmente desencadenaría la Segunda Guerra Mundial.

Así las cosas, la idea detrás del Consejo de Seguridad de las Naciones Unidas (CSNU) fue concebida por Franklin D. Roosevelt, quien en 1941 discutió con Winston Churchill la posibilidad de que las cuatro potencias (Reino Unido, Estados Unidos, China y la Unión Soviética) vigilaran el mundo. De igual forma, estas cuatro naciones fueron las signatarias iniciales de la Declaración de las Naciones Unidas, el 1 de enero de 1942, la cual formaliza el pacto de cooperación entre los Aliados de la Segunda Guerra Mundial.

Roosevelt hizo referencia a los "cuatro policías", en 1942, cuando le presentó al ministro de relaciones exteriores soviético Vyacheslav Molotov sus 
planes para la postguerra. Cada uno de los 'policías' estaría a cargo de vigilar y mantener el orden en una región particular del mundo bajo su esfera de influencia. Reino Unido en Europa Occidental y los dominios de su imperio, la Unión Soviética en Europa Oriental y Eurasia, China en Asia Oriental y el Pacífico Occidental, mientras que los Estados Unidos estarían a cargo en el hemisferio occidental (continente americano).

La Declaración de las Cuatro Naciones, de 1943, estableció la base para la creación de una organización global tras la guerra, la cual reemplazaría a la Liga de las Naciones. Esta intención se materializó en 1944 con la Conferencia de Dumbarton Oaks, donde se establecieron las bases de la Organización de las Naciones Unidas y se determinaron los roles de los miembros permanentes del Consejo de Seguridad. La Carta de las Naciones Unidas fue finalizada durante la Conferencia de San Francisco, en 1945, donde finalmente se estableció el poder de veto de los miembros del CSNU que, a partir de ese momento, incluyó a Francia.

Teniendo en cuenta que la ONU constituye la materialización del enfoque de la seguridad colectiva, es importante dilucidar en las líneas subsiguientes cómo esta organización ha tratado de abordar la seguridad desde un enfoque multidimensional, partiendo del análisis de diversos componentes tales como la seguridad humana, la seguridad biológica, la seguridad ambiental, la seguridad democrática y, en general, la seguridad internacional, todos ellos, conceptos tomados de los informes y resoluciones de la Asamblea General y el Consejo de Seguridad.

Como ya se dijo, la ONU se encuentra cimentada en la necesidad de preservar a las generaciones venideras del flagelo de la guerra, reafirmar la fe en los derechos fundamentales, promover el progreso social y elevar el nivel de vida dentro de un concepto más amplio de libertad. Así mismo, tiene la tarea de crear las condiciones necesarias para el mantenimiento de la justicia y el respeto a las obligaciones emanadas de los tratados y otras fuentes del derecho internacional.

A su vez, responde a unos principios básicos, consignados en el artículo 2 de la Carta de San Francisco, los cuales se resumen en la igualdad soberana de los Estados; el principio de la buena fe; el arreglo pacífico de 
controversias internacionales; el no uso de la fuerza contra la integridad territorial o la independencia política de los Estados; prestar ayuda en cualquier acción que se ejerza de conformidad con la Carta; y la no intervención en los asuntos internos de los Estados.

En un escenario internacional tan complejo como el que supone el siglo XXI, para Naciones Unidas es un reto plasmar un concepto más amplio de seguridad colectiva, por lo cual, de acuerdo con Juliana Tenorio (2009), la ONU debe basar su sistema en tres pilares fundamentales:

1) las amenazas actuales no respetan las fronteras nacionales, están relacionadas entre sí, y deben encararse en los planos mundial, regional y nacional; 2) ningún Estado, por más poderoso que sea, puede hacerse invulnerable por sí solo a dichas amenazas; y 3) no se puede suponer que todo Estado podrá o querrá siempre cumplir su deber de proteger a su propia población y no causar daño a sus vecinos. (p. 184)

En este sentido, el reto fundamental está en implementar un marco de acción preventiva con relación a las amenazas antes mencionadas, el cual se encuentra fundamentado en el desarrollo y la libertad humana.

Ahora bien, ¿cuáles son los mecanismos del sistema de seguridad colectiva de Naciones Unidas para garantizar el mantenimiento de la paz y la seguridad internacionales?

Con el fin de cumplir su mandato y actuar bajo los principios antes descritos, la ONU dividió sus funciones en seis órganos principales: la Asamblea General, el Consejo de Seguridad, el Consejo Económico y Social, el Consejo de Administración Fiduciaria, la Corte Internacional de Justicia y la Secretaría. Como se verá más adelante, sus órganos subsidiarios son una pieza clave para el empleo de los mecanismos de resolución de conflictos.

De acuerdo con el capítulo $\mathrm{V}$ de la Carta, los poderes otorgados al Consejo de Seguridad se encuentran definidos en los capítulos VI, VII, VIII y XII, referentes al arreglo pacífico de controversias; la acción en caso de amenazas a la paz, quebrantamiento de la paz o actos de agresión; los acuerdos regionales; y al régimen internacional de la administración fiduciaria, respectivamente.

El Consejo de Seguridad (en adelante CSNU) está constituido por quince miembros de los cuales cinco son permanentes. Los miembros permanentes de 
este órgano se derivan de los 'cuatro policías' acuñados por Roosevelt durante la Segunda Guerra Mundial, además de Francia. El poder de veto se extiende más allá de las eventuales deliberaciones del CSNU e incluyen la admisión de Estados miembros, así como la nominación de candidatos al cargo de secretario general. Los miembros restantes del órgano son elegidos cada dos años, con lo que se busca una representación geográfica global. La presidencia del CSNU se rota alfabéticamente con base en los nombres de los Estados miembros del consejo; sus funciones van desde presidir las reuniones, hasta emitir declaraciones presidenciales y atender medios de comunicación

En consecuencia, es en los capítulos VI y VII donde se encuentran enmarcados los mecanismos del sistema de Naciones Unidas para la resolución de conflictos, los cuales han ido evolucionando desde la segunda mitad del siglo $\mathrm{XX}$, hasta materializarse en diversas iniciativas, como las misiones de paz, la responsabilidad de proteger, el enfoque de seguridad humana, entre otras.

El capítulo VI, relativo al arreglo pacífico de controversias, propende por buscar soluciones a aquellas que sean susceptibles de poner en riesgo el mantenimiento de la paz y la seguridad internacionales, mediante diversas herramientas como la negociación, la investigación, la mediación, la conciliación, el arbitraje, el arreglo judicial, recurso a organismos o acuerdos regionales, y demás medios pacíficos.

Este rol de intermediación puede ser iniciativa del CSNU o de los Estados miembros que decidan llevar cualquier controversia a ese órgano y a la Asamblea General, e incluso de los Estados que no son miembros, pero que desean solicitar apoyo de Naciones Unidas, siempre y cuando acepten de antemano el cumplimiento de las obligaciones resultantes del arreglo pacífico.

El capítulo VII, relativo a la acción en caso de amenazas a la paz, quebrantamientos de la paz o actos de agresión, habilita al CSNU para hacer recomendaciones o tomar decisiones con respecto a las medidas que se deben tomar para el mantenimiento o restablecimiento de la paz y la seguridad internacionales.

Dentro de las medidas que no implican el uso de la fuerza armada, se encuentran la interrupción parcial o total de las relaciones económicas, las comunicaciones y las relaciones diplomáticas; y en caso de que estas medidas 
resulten inadecuadas, el CSNU puede ejercer, por medio de las fuerzas terrestres, aéreas o navales, acciones como demostraciones, bloqueos y otras operaciones ejecutadas por las fuerzas armadas de miembros de la ONU.

Para tales fines, los miembros deben poner a disposición del CSNU las fuerzas armadas, la ayuda y las facilidades, e incluso el derecho de paso, para el propósito de mantener la paz y la seguridad; además, deben mantener contingentes de fuerzas aéreas nacionales disponibles de inmediato para la ejecución combinada de una acción coercitiva de carácter internacional.

Como se verá a continuación, la ONU cuenta con diversos órganos subsidiarios que, en coordinación con los órganos principales, emplean diferentes estrategias y mecanismos para la resolución de conflictos armados y el mantenimiento de la paz y la seguridad, siendo algunos de estos las resoluciones del CSNU (en su mayoría vinculantes); las misiones de paz; los procesos de desarme, desmovilización y reintegración (DDR); los diferentes fondos y programas; las sentencias de la Corte Penal Internacional (que dentro del sistema de la ONU es considerado como un órgano judicial independiente); entre otros.

\section{La Asamblea General, sus funciones y alcances ante eventuales conflictos}

Dentro de los órganos principales de la Organización de Naciones Unidas, la Asamblea General (en adelante AG) es el único en el que los 193 Estados miembros tienen representación. Este se constituye como el principal escenario participativo para la deliberación y formulación de políticas de alcance global; además es, de facto, el foro en el que se "debaten cuestiones de interés mundial, como el desarrollo sostenible, la paz y la seguridad, el cambio climático, la igualdad de género, etc." (Organización de las Naciones Unidas, 2019).

Las responsabilidades de la AG incluyen la administración del presupuesto de la ONU, la cooperación a favor del mantenimiento de la paz y seguridad internacionales, y el nombramiento tanto de los miembros no permanentes del CSNU como del secretario general.

De igual manera, la AG fomenta la cooperación en materias económica, social, cultural, educativa y sanitaria; además de recibir reportes de sus órganos subsidiarios, fondos, programas e institutos de investigación y capacitación, 
los cuales son fundamentales en materia humanitaria y estrategias a mediano y largo plazo para la resolución de conflictos. Las declaraciones formales adoptadas por la AG se emiten en forma de resoluciones que, a diferencia de las emitidas por el CSNU, no son de obligatorio cumplimiento por los Estados miembros (sin que ello les reste legitimidad e impacto global).

El periodo ordinario de sesiones de la AG se lleva a cabo cada año de septiembre a diciembre. Aunque el desarrollo de estas tiene lugar en la sede de las Naciones Unidas en New York, ante la petición de los Estados miembros, podría eventualmente llevarse a cabo en otro lugar. Durante el periodo ordinario de sesiones se revisan la Memoria del secretario general, los informes del CSNU y del Consejo Económico y Social, así como los informes de todos los órganos subsidiarios cuya información sea relevante para los temas que se vayan a discutir.

Durante las sesiones de la AG también participan observadores, sujetos del derecho internacional público (Estados no miembros) con voz, pero sin voto, como la Misión Permanente de Observación de Palestina y la Misión Permanente de Observación de la Santa Sede. Otras organizaciones internacionales también participan como observadores ante la AG, tal es el caso de la Unión Africana, la Liga de los Estados Árabes y la Unión Europea.

El secretario general está facultado para convocar un periodo extraordinario de sesiones para deliberar sobre actuaciones que requieren una actuación inmediata. De la misma forma, pueden llevarse a cabo periodos extraordinarios de sesiones de emergencia cuando el CSNU se encuentre inoperante por falta de unanimidad de sus miembros permanentes, obligando a la AG a examinar el asunto con el ánimo de proporcionar las recomendaciones adecuadas para restaurar o mantener la paz y seguridad internacionales. Aunque las sesiones son públicas por naturaleza, la AG puede determinar el desarrollo de sesiones privadas, si el tema a tratarse implica tomar esta medida.

Mientras que las recomendaciones asociadas a la paz y la seguridad, la admisión de nuevos miembros y la aprobación de presupuestos requieren una mayoría de dos tercios en la AG, asuntos de otra índole son debatidos y decididos sobre la base democrática de la mayoría simple. Los temas que se debaten durante las sesiones pueden ser propuestos por los órganos de las Naciones 
Unidas, Estados miembros, el secretario general e incluso, por Estados no miembros, siempre y cuando el asunto sea de interés para la organización.

El fundamento normativo de la AG se encuentra consignado en el capítulo IV de la Carta de San Francisco, la cual establece su composición, funciones, poderes, mecanismo de votación y procedimiento. Sin embargo, la AG también cuenta con su propio reglamento, a través del cual se determinan los pormenores procedimentales y organizativos para su adecuado funcionamiento.

Además de la AG, existen otros órganos principales cuyo papel en el mantenimiento de la paz y la seguridad internacionales es fundamental, no solamente en escenarios ordinarios sino, sobre todo, en escenarios de conflicto donde la estabilidad del sistema internacional se ve seriamente amenazada. Tal es el caso del CSNU, del cual ya se habló sucintamente.

\section{Sobre el mantenimiento de la paz y la seguridad internacionales}

Doyle y Sambanis (2007) indican que el éxito en la construcción de la paz radica mayormente en transformar las preferencias de las partes que rivalizan, en lugar de cambiar los incentivos con los que se pretende llegar a un acuerdo. La transformación de las preferencias puede implicar, según ellos, cambiar la naturaleza misma de las partes enfrentadas. Una vez las condiciones son favorables entre las partes, los problemas de coordinación se vuelven problemas de cooperación, lo que implica una aproximación holística y, por tanto, estratégica con respecto a cada conflicto en particular.

El mantenimiento de la paz y seguridad internacionales es una preocupación que se extiende mucho más allá de la prevención de conflictos y la finalización de aquellos en desarrollo. Los conflictos armados son el resultado de una sumatoria de motivaciones políticas, sociales, religiosas, económicas y étnicas, entre otras, que requieren soluciones integrales, con el fin de evitar su escalamiento y la aparición de la violencia.

Dicha integralidad fue abordada por el Informe de Desarrollo Humano de 1994, considerado actualmente el texto fundacional del concepto de 'seguridad humana', que expande el concepto clásico de seguridad territorial heredado del modelo westfaliano del sistema internacional. Ahora bien, aunque 
muchas de las ideas asociadas a la seguridad humana son previas a la creación de este término, solo hasta 1994 el Programa de las Naciones Unidas para el Desarrollo (en adelante PNUD) estableció un marco de referencia lo suficientemente sólido para que esta nueva aproximación se extendiera a lo largo de la comunidad internacional.

A pesar de que la seguridad humana y la seguridad nacional se conciben como complementarias, la primera es particularmente criticada por su amplitud conceptual y su contradicción frente a la visión teórica neorrealista. Esta nueva aproximación a la seguridad propone proteger fundamentalmente al individuo y no al Estado, lo que requiere la intervención en nuevas áreas ${ }^{7}$ para lograr su correcta materialización.

Usando como marco de referencia la visión de seguridad humana propuesta por las Naciones Unidas, cabe resaltar que su intervención para la resolución de conflictos incluye un componente humanitario importante que se operativiza a través de órganos subsidiarios, fondos, programas, comisiones, departamentos, oficinas y organismos especializados.

El mantenimiento de la paz y seguridad internacionales requiere también de un diálogo directo con las partes que rivalizan, la satisfacción de las necesidades básicas del ser humano que, al participar en el conflicto, busca lograr unas condiciones de vida dignas. Entre el sistema de las Naciones Unidas hay entidades particularmente importantes en la búsqueda del desarrollo humano sostenible, en concordancia con los preceptos establecidos por la seguridad humana.

Para efectos de la resolución de conflictos ciertas entidades bajo la supervisión de la AG son particularmente importantes el PNUD, el Fondo de las Naciones Unidas para la Infancia (Unicef), la Oficina del Alto Comisionado de las Naciones Unidas para los Refugiados (Acnur), ONU-Mujeres, el Programa Mundial de Alimentos (PMA) y el Programa de las Naciones Unidas para el Medio Ambiente (PNUMA).

El Consejo Económico y Social, órgano principal de la ONU es igualmente importante en la coordinación de las comisiones orgánicas, regionales

7 Seguridad económica, seguridad alimentaria, seguridad de la salud, seguridad ambiental, seguridad personal, seguridad comunitaria y seguridad política. 
y otros órganos afines a su misionalidad. Sin embargo, cabe resaltar que muchas de sus funciones se traslapan con las de la AG que, al contar con una participación absoluta de todos los Estados miembros, goza de mayor legitimidad para la toma de determinaciones en materia humanitaria, ambiental, económica y social.

Una vez finalizada la Guerra Fría, el interés de la ONU por el mantenimiento de la paz se dinamizó de forma considerable. En 1992, el secretario general de las Naciones Unidas, Boutros Boutros-Ghali, estableció las bases fundacionales y conceptuales sobre la paz global en su reporte "An agenda for peace: Preventive diplomacy, peacemaking and peace-keeping". Para BoutrosGhali, además de la diplomacia preventiva, cuatro roles interdependientes eran fundamentales para que las Naciones Unidas jugaran un papel fundamental en el mantenimiento de la paz en el periodo posterior Guerra Fría:

1. Consolidación de la paz (peace making): por medio del uso de las herramientas establecidas en el capítulo VI de la Carta de San Francisco, la consolidación de la paz busca lograr un acuerdo pacífico entre las partes enfrentadas a través de la mediación, negociación o acuerdos jurídicos.

2. Mantenimiento de la paz y seguridad (peace keeping): corresponde a la presencia de las Naciones Unidas sobre el terreno con el consentimiento de las partes involucradas y en concordancia con el capítulo VI de la Carta. Las fuerzas militares bajo la bandera de las Naciones Unidas carecen de armamento pesado y son, en gran medida, un mecanismo para el restablecimiento de la confianza durante una tregua. $\mathrm{Al}$ mismo tiempo, diplomáticos y otros funcionarios civiles buscarán negociar un acuerdo de paz que finalice oficialmente el conflicto y garanticen la entrega de ayuda humanitaria.

3. Imposición de la paz (peace enforcement): se trata de una actividad con o sin autorización de las partes, con la finalidad de hacer cumplir un cese al fuego. Esta medida es impuesta por el CSNU bajo la autoridad que le otorga el capítulo VII de la Carta de San Francisco. Las fuerzas inmersas en esta clase de operaciones se encuentran bajo el 
mandato del secretario general y cuentan con los recursos técnicos, humanos y operacionales que les brindan una superioridad militar frente a las partes enfrentadas.

4. Construcción de la paz en el postconflicto (post-conflict peace-building): estas actividades están orientadas al establecimiento de proyectos cooperativos después de un conflicto entre dos o más países, no solo con el fin de contribuir al desarrollo social y económico mutuo, sino también al mejoramiento de las relaciones y la confianza entre las partes. Intereses en común, como el desarrollo agrícola, infraestructura vial, uso de recursos hídricos, educación, entre otros, pueden permitir la cooperación entre antiguos adversarios.

El mantenimiento de la paz es actualmente una función del Departamento de Operaciones de Paz (en adelante DOP). Los antecedentes para la creación de este departamento se remontan a la creación, en 1948, del Grupo de Observadores Militares de las Naciones Unidas en India y Pakistán (UNMOGIP) y el Organismo de Vigilancia de la Tregua (ONUVT), en Oriente Medio. Hasta finales de la década de los ochenta, las operaciones de mantenimiento de paz eran llevadas a cabo a través de la Oficina de Asuntos Especiales de la ONU, lo que eventualmente gestó el nacimiento del DOP, en 1992, como entidad constituida específicamente para esta clase de actividades.

En la actualidad, existen 14 operaciones de mantenimiento de paz distribuidas principalmente en África y Oriente Medio, además de dos recientes localizadas en Kosovo y Cachemira.

Tabla 1. Operaciones de mantenimiento de paz en la actualidad

\begin{tabular}{lccll}
\hline \multicolumn{1}{c}{ Nombre } & Acrónimo & Lugar & Año & \multicolumn{1}{c}{ Función } \\
\hline Organismo de las & ONUVT & Oriente Medio & 1948 & Supervisar el alto el fuego y los \\
Naciones Unidas & & & & acuerdos de armisticio, evitar \\
para la Vigilancia & & & que incidentes aislados alcancen \\
de la Tregua & & & mayores proporciones y ayudar \\
& & & a otras operaciones de mante- \\
& & & nimiento de la paz en la zona a \\
& & & cumplir sus mandatos. \\
\hline
\end{tabular}




\begin{tabular}{|c|c|c|c|c|}
\hline Nombre & Acrónimo & Lugar & Año & Función \\
\hline $\begin{array}{l}\text { Grupo de } \\
\text { Observadores } \\
\text { Militares de las } \\
\text { Naciones Unidas } \\
\text { en la India y el } \\
\text { Pakistán }\end{array}$ & Unmogip & $\begin{array}{l}\text { India y } \\
\text { Pakistán }\end{array}$ & 1949 & $\begin{array}{l}\text { Supervisar el alto el fuego entre la } \\
\text { India y el Pakistán en el estado de } \\
\text { Jammu y Cachemira. }\end{array}$ \\
\hline $\begin{array}{l}\text { Fuerza de } \\
\text { las Naciones } \\
\text { Unidas para el } \\
\text { Mantenimiento } \\
\text { de la Paz en } \\
\text { Chipre }\end{array}$ & Unficyp & Chipre & 1964 & $\begin{array}{l}\text { Impedir nuevos enfrentamientos } \\
\text { entre las comunidades grecochi- } \\
\text { priota y turcochipriota, así como } \\
\text { llevar a cabo actividades humani- } \\
\text { tarias y apoyar la misión de buenos } \\
\text { oficios del secretario general. }\end{array}$ \\
\hline $\begin{array}{l}\text { Fuerza de las } \\
\text { Naciones Unidas } \\
\text { de Observación } \\
\text { de la Separación }\end{array}$ & FNUOS & Golán & 1974 & $\begin{array}{l}\text { Vigilar el alto el fuego entre Siria } \\
\text { e Israel y supervisar el acuerdo de } \\
\text { retirada. }\end{array}$ \\
\hline $\begin{array}{l}\text { Fuerza } \\
\text { Provisional de las } \\
\text { Naciones Unidas } \\
\text { en el Líbano }\end{array}$ & FPNUL & Líbano & 1978 & $\begin{array}{l}\text { Supervisar el cese de las hosti- } \\
\text { lidades entre Líbano e Israel y } \\
\text { garantizar el apoyo humanitario a } \\
\text { la población civil. }\end{array}$ \\
\hline $\begin{array}{l}\text { Misión de } \\
\text { las Naciones } \\
\text { Unidas para el } \\
\text { Referéndum del } \\
\text { Sahara Occidental }\end{array}$ & Minurso & $\begin{array}{c}\text { Sahara } \\
\text { Occidental }\end{array}$ & 1991 & $\begin{array}{l}\text { Aceptar, el } 30 \text { de agosto de } 1988, \\
\text { las propuestas de arreglo por parte } \\
\text { de Marruecos y el Frente Popular } \\
\text { para la Liberación de Saguía } \\
\text { el-Hamra y de Río de Oro (Frente } \\
\text { Polisario). }\end{array}$ \\
\hline $\begin{array}{l}\text { Misión de } \\
\text { Administración } \\
\text { Provisional de las } \\
\text { Naciones Unidas } \\
\text { en Kosovo }\end{array}$ & Unmik & Kosovo & 1999 & $\begin{array}{l}\text { Promover la seguridad, la estabi- } \\
\text { lidad y el respeto de los derechos } \\
\text { humanos en Kosovo. }\end{array}$ \\
\hline $\begin{array}{l}\text { Operación } \\
\text { Híbrida de la } \\
\text { Unión Africana } \\
\text { y las Naciones } \\
\text { Unidas en Darfur }\end{array}$ & Unamid & Darfur & 2007 & $\begin{array}{l}\text { Proteger a los civiles, facilitar } \\
\text { ayuda humanitaria y ayudar al } \\
\text { proceso político en Darfur. }\end{array}$ \\
\hline
\end{tabular}




\begin{tabular}{|c|c|c|c|c|}
\hline Nombre & Acrónimo & Lugar & Año & Función \\
\hline $\begin{array}{l}\text { Misión de } \\
\text { Estabilización } \\
\text { de las Naciones } \\
\text { Unidas en } \\
\text { la República } \\
\text { Democrática del } \\
\text { Congo }\end{array}$ & Monusco & $\begin{array}{l}\text { República } \\
\text { Democrática } \\
\text { del Congo }\end{array}$ & 2010 & $\begin{array}{l}\text { Proteger a los civiles y consolidar la } \\
\text { paz en la República Democrática } \\
\text { del Congo. }\end{array}$ \\
\hline $\begin{array}{l}\text { Misión de } \\
\text { Asistencia de las } \\
\text { Naciones Unidas } \\
\text { en la República } \\
\text { de Sudán del Sur }\end{array}$ & Unmiss & Sudán del Sur & 2011 & $\begin{array}{l}\text { Proteger a los civiles, vigilar los } \\
\text { derechos humanos y apoyar la } \\
\text { prestación de asistencia humani- } \\
\text { taria y la aplicación del acuerdo de } \\
\text { cese de hostilidades. }\end{array}$ \\
\hline $\begin{array}{l}\text { Fuerza } \\
\text { Provisional de } \\
\text { Seguridad de las } \\
\text { Naciones Unidas } \\
\text { para Abyei }\end{array}$ & Unisfa & Abyei & 2011 & $\begin{array}{l}\text { Desmilitarizar Abyei y permitir el } \\
\text { ingreso de las tropas etíopes a la } \\
\text { zona. }\end{array}$ \\
\hline $\begin{array}{l}\text { Misión } \\
\text { Multidimensional } \\
\text { Integrada de } \\
\text { Estabilización } \\
\text { de las Naciones } \\
\text { Unidas en Malí }\end{array}$ & Minusma & Malí & 2013 & $\begin{array}{l}\text { Apoyar el proceso político y ayudar } \\
\text { la estabilización de Malí. }\end{array}$ \\
\hline $\begin{array}{l}\text { Misión } \\
\text { Multidimensional } \\
\text { Integrada de } \\
\text { Estabilización } \\
\text { de las Naciones } \\
\text { Unidas en } \\
\text { la República } \\
\text { Centroafricana }\end{array}$ & Minusca & $\begin{array}{c}\text { República } \\
\text { Centroafricana }\end{array}$ & 2014 & $\begin{array}{l}\text { Apoyar el proceso de transición, } \\
\text { facilitar la asistencia humanitaria, } \\
\text { promover y proteger los derechos } \\
\text { humanos, ayudar a la justicia y } \\
\text { el estado de derecho, apoyar los } \\
\text { procesos de desarme, desmovili- } \\
\text { zación, reintegración y de repa- } \\
\text { triación. }\end{array}$ \\
\hline
\end{tabular}

Fuente:

Si bien estas operaciones han contribuido a la construcción y consolidación de la paz en diversas regiones del globo, los retos del sistema de Naciones Unidas son cada vez más grandes, teniendo en cuenta sus limitaciones, la naturaleza cambiante de los métodos de violencia y los actores involucrados en los conflictos armados contemporáneos. 
A este respecto, en los capítulos subsiguientes se abordarán tres conflictos modernos como casos de estudio, con el fin de evidenciar la increíble complejidad de las guerras actuales y los retos que estas imponen, particularmente a la Organización de las Naciones Unidas. Se observará a través del análisis de los casos de estudio que los mecanismos para la resolución de conflictos con que cuenta la ONU resultan insuficientes para darle un adecuado manejo al reto actual de las guerras subsidiarias a través de actores no estatales.

\section{Referencias}

Boutros-Ghali, B. (1992). An Agenda for Peace: Preventive Diplomacy, Peacemaking and PeaceKeeping. International Relations, 11(3), 201-218.

Deulofeu, A. (1967). La matemática de la historia. Editorial Emporitana.

Doyle, M., \& Sambanis, N. (2007). The UN Record on Peacekeeping Operations. International Journal, 62(3), 495-518. https://doi.org/10.1177/002070200706200304

Encel, F. (2011). Comprendre la géopolitique. Points.

Fieldhouse, D. (1961). Imperialism: An Historiographical Revision. The Economic History Review, 14(2), 187-209.

Hardt, M., \& Negri, A. (2001). Empire. Harvard University Press.

Herrera, L., \& González, G. (1990). Balance y perspectivas en el uso del concepto del concepto de seguridad nacional en el caso de México. En S. Aguayo, \& B. Bagley (comp.), En busca de la seguridad perdida: Aproximaciones a la seguridad nacional mexicana (pp. 391-410). Siglo XXI Editores.

Hobson, J. A. (1902). Imperialism: A Study (1. ed.). James Pott \& Co. http://files.libertyfund. org/files/127/0052_Bk.pdf

Instituto Español de Estudios Estratégicos. (2011). La evolución del concepto de seguridad. Ministerio de Defensa. http://www.ieee.es/Galerias/fichero/docs_marco/2011/DIEEEM052011EvolucionConceptoSeguridad.pdf

Kennedy, P. (2017). Auge y caida de las grandes potencias. Penguin Random House Grupo Editorial Espańa.

Lenin, V. (1916). Imperialismo: la fase superior del capitalismo. Fundación Federico Engels.

Lourdes, D. (2017). La paz, la seguridad colectiva y el desarrollo. Revista AFESE, 21(21), 122-133.

Mazarr, M., Blake, J., Casey, A., McDonald, T., Pezard, S., \& Spirtas, M. (2018). Understanding the Emerging Era of International Competition: Theoretical and Historical Perspectives. RAND corporation. https://www.rand.org/pubs/research_reports/RR2726.html 
Medina-Núnez, I. (2019). El concepto Realpolitik en la ciencia política. Espiral, 26(76), 281-290. https://doi.org/10.32870/eees.v26i76.7023

Moreau, P. (2017). Nouvelles relations internationales (2. ${ }^{\text {e }}$ d.). Presses de Sciences Po. https:// www.eyrolles.com/Entreprise/Livre/nouvelles-relations-internationales-9782757857342/

Negretto, G. (2000). Kant y la ilusión de la seguridad colectiva. https://studylib.es/doc/287586/ kant-y-la-ilusion-de-la-seguridad-colectiva

Organización de las Naciones Unidas. (2019, septiembre 18). $74^{\circ}$ período de sesiones de la Asamblea General UNGA. Naciones Unidas Colombia. https://nacionesunidas.org.co/noticias/74-periodo-de-sesiones-de-la-asamblea-general

Rodney, W. (1973). How Europe Underdeveloped Africa. Publishing House.

Schumpeter, J. (1919). The Sociology of Imperialisms. Laissez Faire Books.

Sunga, L. (Ed.). (2016). The Concept of Human Security: Does it Add Anything of Value to International Legal Theory or Practice? En M. Frick, \& A. Oberprantacher (Eds.), Power and Justice in International Relations: Interdisciplinary Approaches to Global Challenges (pp. 131-148). Ashgate.

Tenorio, M. (2009). La evolución del concepto de seguridad y la transformación de la seguridad colectiva en la ONU. Criterios, 2(2), 171-197.

Terradas, N. (2009). El dilema de seguridad y su importancia para el estudio de las relaciones internacionales. Enfoques, (88-3), 1-5. https://revistas.ort.edu.uy/letras-internacionales/ article/view/1627

Veblen, T. (1903). Review of J. A. Hobson "Imperialism: A Study". Journal of Political Economy, 11(2), 311-314. 